\title{
Differential evolution algorithm for identification of structural damage in steel beams
}

\author{
Brunno E. Sobrinho, Gilberto Gomes, Welington V. da Silva, Ramon S. Y. R. C. Silva, Luciano \\ M. Bezerra \\ University of Brasilia, Brazil \\ brunno.emidi@@aluno.unb.br,bttps://orcid.org/0000-0003-4407-7213 \\ ggomes@unb.br,bttp://orcid.org/0000-0002-8385-9042 \\ welington.vital@aluno.unb.br,ramon@unb.br,lmbz@unb.br
}

Erwin U. L. Palechor

University of Cariri Juazeiro do Norte, Ceará, Brazil

erwin.lopez@ufca.edu.br

\begin{abstract}
Problems involving errors and uncertainties from the use of numerical and experimental responses of beams using optimization processes have been studied by many researchers. In this field, to simulate the real behavior of structures, especially in problems involving damage, it is required to have reliable experimental results in order to adjust a numerical model. These difficulties may be associated for example to the modeling of the connection stiffness, support conditions, or relevant parameters in structures involving damages. This paper proposes a new methodology to detect damage in steel beams using the Differential Evolution Technique based on experimental and numerical data. The results show a great potential of the methodology to solve damage detection problems.
\end{abstract}

KEYwORDS. Steel beams; Optimization; Damage identification; Differential Evolution.

\section{open ACcess}

Citation: Sobrinho, B., Gomes, G., V. Silva, W., Silva, R., Bezerra, L, Palechor, E. Differential Evolution Algorithm for Identification of Structural Damage in Steel Beams, Frattura ed Integrità Strutturale, 52 (2020) 51-66.

Received: 19.09 .2019

Accepted: 17.01 .2020

Published: 01.04 .2020

Copyright: (C) 2020 This is an open access article under the terms of the CC-BY 4.0, which permits unrestricted use, distribution, and reproduction in any medium, provided the original author and source are credited.

\section{INTRODUCTION}

$\mathrm{I}$ $\mathrm{n}$ recent years researchers have dedicated considerable attention to optimization procedures. The real behavior of structures is not easy to be simulated due to the complexity in modeling the stiffness of connections, support conditions and other parameters. Therefore, the damage identification process becomes more difficult.

On the other hand, the inverse problems area has a great potentiality to deal with damaged structures. According to [1], the damage identification is done by numerical methods, which seek the identification of geometric parameters of a model adopted for damage, from the structural response (static, dynamic, electrical, thermal excitation, among others). A powerful 
and well-known technique used to detect damage in structures is based on Wavelet Transform, which can be applied using the damaged condition of the structure; see for example [2, 3, 4].

The inverse problem to find and to identify damage in a structure, as seen in [5], is solved by two different and independent approaches, one based on optimization (using a genetic algorithm) and the other one based on a parameter identification (using a neural network). In [6], it is pointed out that the optimization algorithms have a flexibility of implementation because the evaluation scheme customizes the algorithm for a specific purpose.

This paper proposes a new methodology in the context of the Structural Health Monitoring Methods, using Differential Evolution to detect damage in steel beams on the basis of numerical and experimental results.

\section{OPTIMIZATION ALGORITHMS}

\section{Differential Evolution Algorithms}

ccording to [7], the main goal of the optimization algorithms is to find the ideal solution for a given problem, A whereas it can achieve the objectives that have been established with the least cost and / or maximum efficiency. 11 The Differential Evolution (DE) method, proposed by [8], is a heuristic approach for minimizing possibly nonlinear and non-differentiable continuous space functions. The DE method has been presented with a simple, but powerful numerical optimization algorithm for global optimal solution search and has been successfully applied in complex optimization problems.

The DE method uses algorithms that are based on population of individuals. Each individual represents a search point in the space of potential solutions to a given problem and imitates nature principles to create optimization procedures. This method has selection procedures based on the individual fitness, crossover and mutation operators. Fig. 1 shows the flowchart of DE algorithms presented in [9]. The main procedure of DE includes four phases, such as initiation, mutation, crossover and selection.

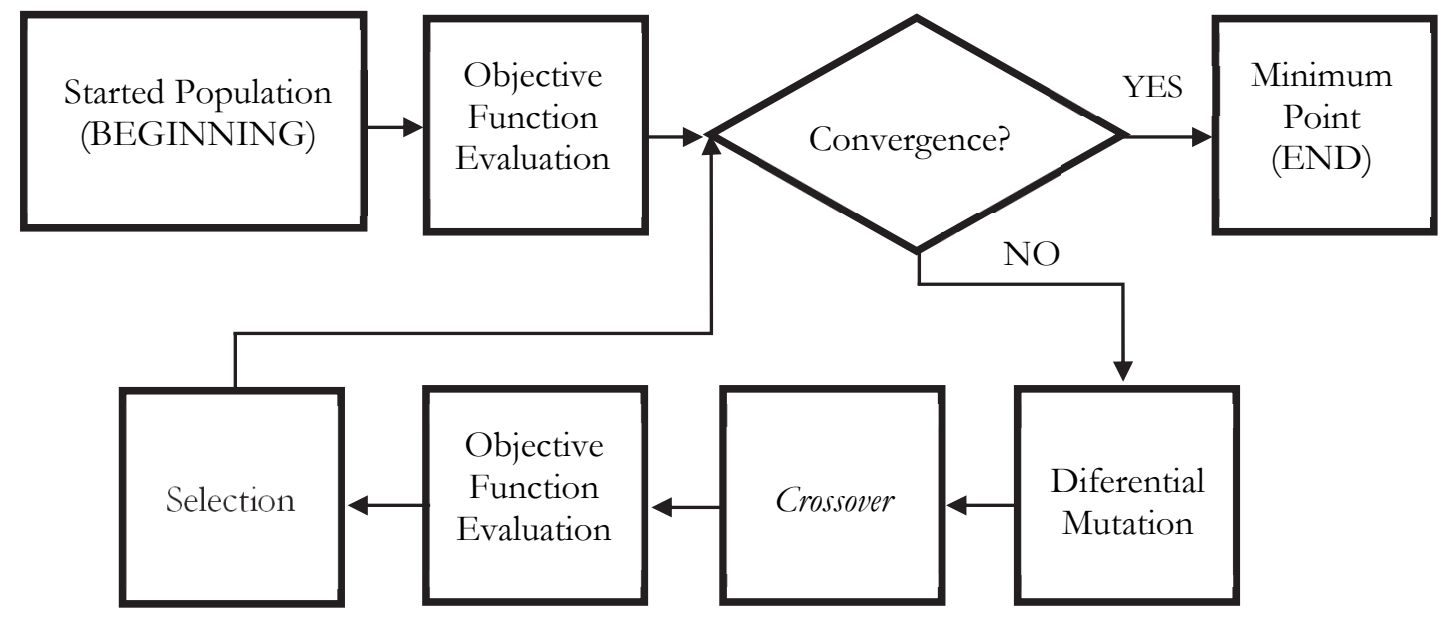

Figure 1: Differential Evolution (DE) method flowchart [9].

In [10], other mechanisms that can be used to finish the evolutionary process are referred: the processing time, the evaluations number of the objective function, the final value of the objective function and own user monitoring. It must be emphasized that it seems always to converge with a low computational effort using numerical evaluations of objective functions.

\section{The optimization problem}

The optimization algorithms involve well-defined mathematical formulations, in which a set of variables describes the system, called design variables. Both the objective function and project restrictions can have features of analyses or synthesis of design, for example, minimizing the mass of a structure in order to find a specified stress limit.

As defined in [11], the optimization problem, or determining the minimum, is composed as follows:

- Objective function: it is the mathematical function $f(p)$ to be optimized;

- Design variables: these are the independent variables that appear in the objective function; 
- Restrictions: these are the limits imposed to the system, or established by natural laws that govern the system, subjected to the design variables;

- Search region: it is the space region defined by the variable of project and delimited by the restrictions, where the interior or border locates the optimal objective function.

A general scheme of an optimization problem is shown in Fig. 2, in which can observe that the method intends to find the minimum local points.

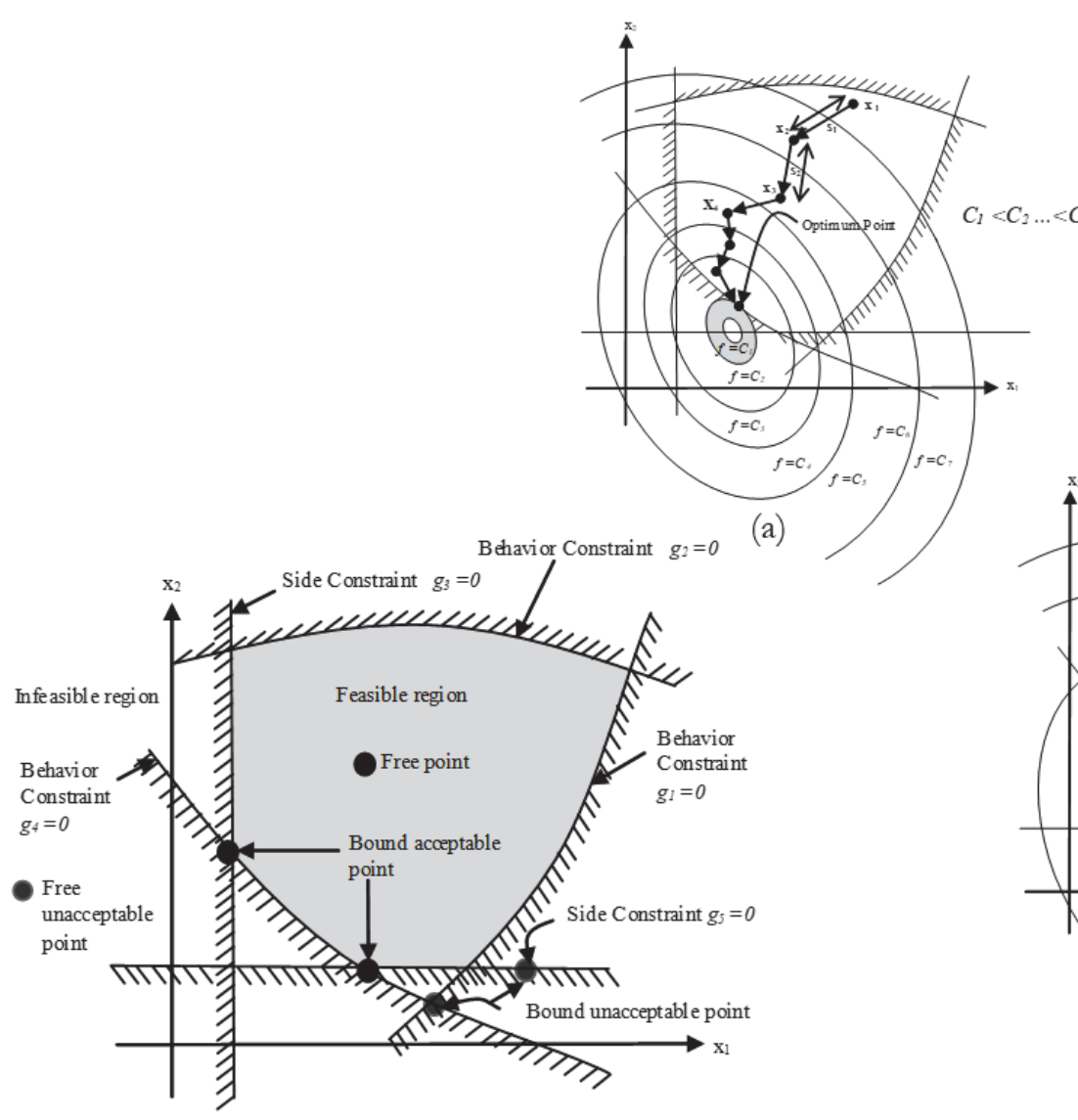

(b)

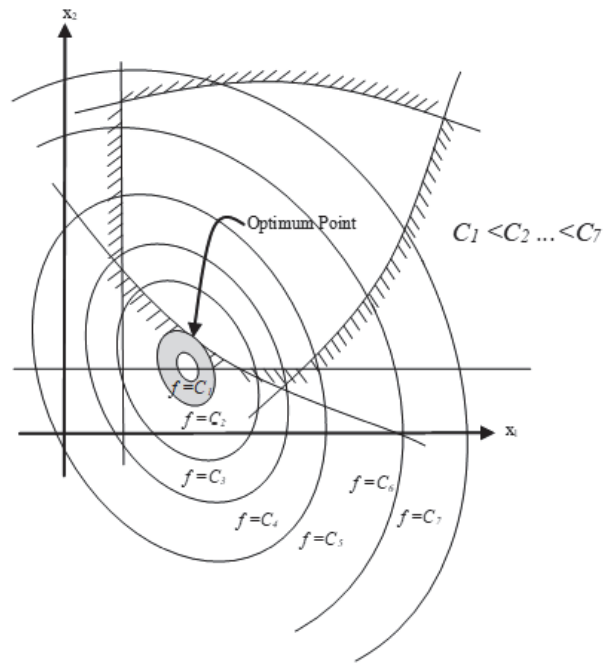

(c)

Figure 2: General schemes of an optimization problem: (a) Optimization Method; (b) Constraint; (c) Objective Function.

\section{STRUCTURAL DAMAGE FORMULATION}

he identification, localization and quantification of stiffness loss of a system from the static or dynamic response of the structure are important indicators to damage detection procedure. The natural frequencies tend to decrease as the damage increases its dimensions [12], and the modal amplitude values at damaged positions also tends to decrease.

The effect of a structural damage can be classified as linear and non-linear. The first case is a situation where the structure is initially in the linear elastic domain and remains in this same domain after the damage appearance. For the second case, the initial behavior of the structure is linear and after a high level of damage the behavior becomes non- linear, as in the case of fatigue cracks due to cyclic loads or after the plastification of certain elements due to a crash, for example [13]. In a static analysis, the basic formulation used is presented in following Eqn. (1).

$$
([\mathrm{K}][\mathrm{x}])=[P]
$$


where "K" is the stiffness matrix; " $\mathrm{x}$ " is the static displacements vector and "P" are the nodal loads.

It is important to remember that the differences with specific elements of the matrices make possible the damages evaluation. The hypothesis that the mass matrix is constant is considered when the internal damage does not result in material loss.

These parameters can be related, in the stiffness matrix, to a series of variables, as following Eqn. (2).

$$
\mathrm{K}=[\mathrm{K}(\mathrm{A}, t, l, E, I, G, J)]
$$

where " $\mathrm{A}$ " is the area, " $\mathrm{t}$ " is thickness, "l" is the length, " $\mathrm{E}$ " is the Young's modulus, "I" represents the longitudinal moment of inertia, "G" is transverse elasticity modulus and " $\mathrm{J}$ " is the torsional moment of inertia. Parameter $[\mathrm{K}]$ shown in Eqn. (2) is identified and used for the static equilibrium equation.

This research is limited to the use of only static responses in terms of displacement which is the variable that changes its value due to the damage presence. This variable, named "di", minimizes the objective scalar function " $F$ " that represents the difference between the analytical response (intact structure) and the experimental one (damaged structure). The following Eqn. (3) contemplates:

$$
F=\sum_{i} \sum_{j}\left(Y_{m}^{i j}-Y_{a}^{i j}\right)^{2}
$$

where $Y_{m}^{i j}$ are the static displacements measured (intact structure), $Y_{a}^{i j}$ are the static displacements obtained analytically (damaged structure), " $\mathrm{i}$ " is the degree of freedom and " $\mathrm{j}$ " is the static shipment condition in a particular case.

The stiffness matrix of each beam element was modified to incorporate the damage variable, as the expression of the beam element. For a beam element, though the following Eqn. (4), the stiffness matrix establishes how the physical and material properties are stored and also how each beam is modified to incorporate the variable damage.

$$
\left[K_{j}\right]=\frac{E\left(1-\left[d_{i}\right]\right)}{l^{3}}\left[\begin{array}{cccccc}
A l^{2} & 0 & 0 & -A l^{2} & 0 & 0 \\
0 & 12 I & 6 I l & 0 & -12 I & 6 I l \\
0 & 6 I l & 4 I l^{2} & 0 & -6 I l & 2 I l^{2} \\
-A l^{2} & 0 & 0 & A l^{2} & 0 & 0 \\
0 & -12 I & -6 I l & 0 & 12 I & -6 I l \\
0 & 6 I l & 2 I l^{2} & 0 & -6 I l & 4 I l^{2}
\end{array}\right]_{6 \times 6}
$$

where [di] is the variable design vector and, the variable design vectors "di" shown in Eqn. (4), could assume values between 0 (intact element) and 1 (damaged element).

\section{EXPERIMENTAL PROGRAM}

I

$\mathrm{n}$ this section, the considered experimental program, based on the results obtained by [15] is presented. Two simply supported I steel beams characterized by two different loading schemes, as illustrated in Fig. 3 were simulated. The beam properties are presented in Tab. 1.

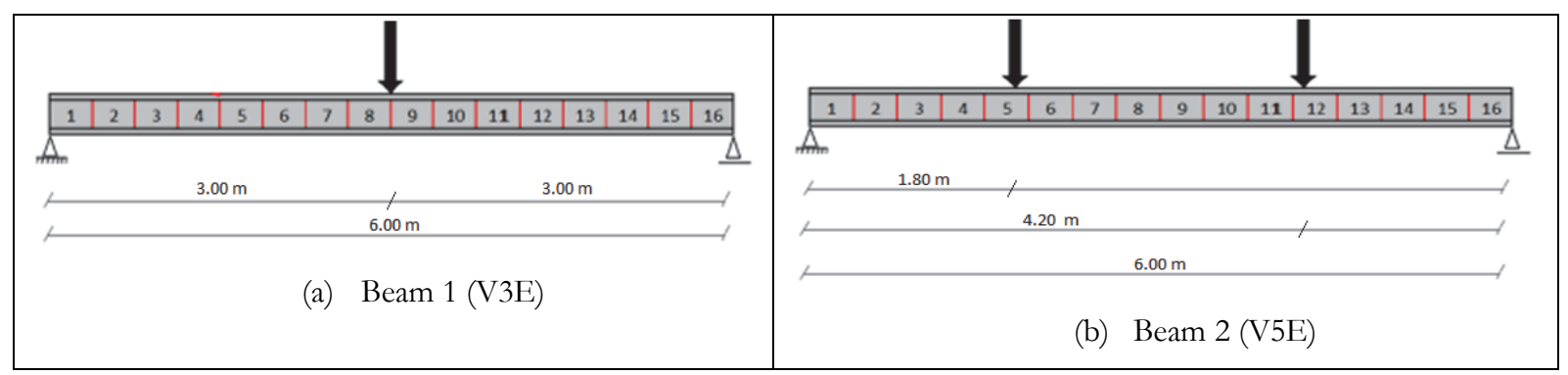

Figure 3: Schematic models of the beams analyzed. 


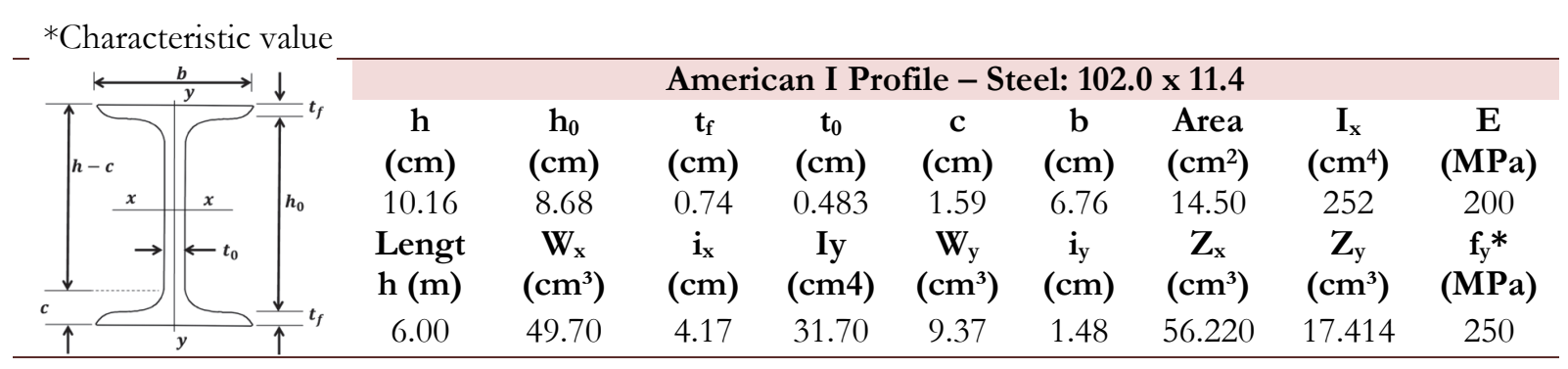

Table 1: Beam geometric, mass, and mechanical properties.

According to [14], the load stages used for evaluation with the optimization methods refer to those immediately before the maximum load. Damage was induced through notches transverse to the longitudinal axis of the beams (Fig. 4b). It is worth noticing that the adoption of these open vertical cracks can be caused by diverse demands, such as behaviors found in buildings with metallic structural elements.
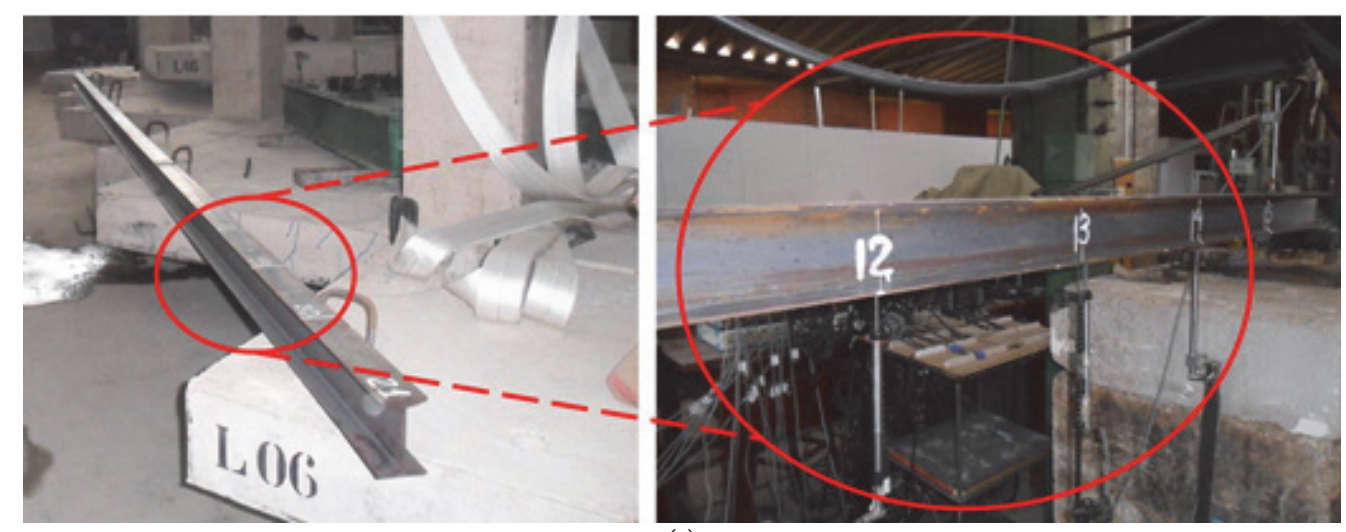

(a)

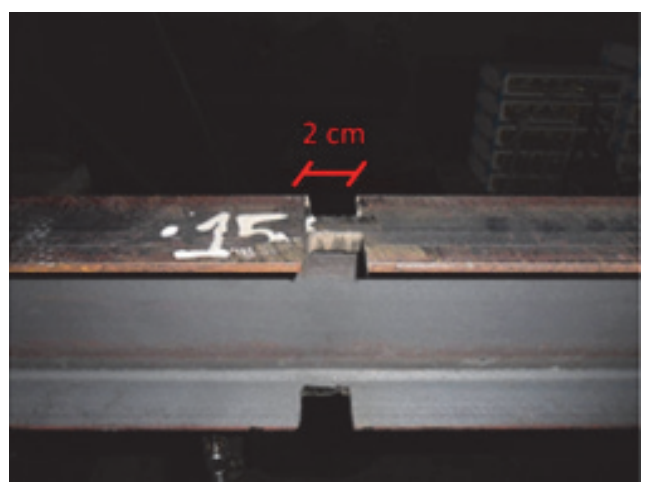

(b)

Figure 4: Beams overview: (a) 16 - element beam subdivision and (b) induced damage - $2 \mathrm{~cm}$ [15].

The beams tested were divided into 16 parts (see Fig. 4a) and one Linear Variable Differential Transformer (LVDT) was positioned in each element. Fig. 5 shows the 15 internal points and LVDT's positions. Figs. 6 and 7 report details of the support conditions and the loading arrangement, respectively.

The loading was applied in a vertical upward direction in loading steps, taking into account the maximum load value supported by the intact beam so as not to suffer local buckling. These load values chosen for the application of the proposed damage identification method were lower than the calculated maximum load value. The loads were chosen in service stage. The maximum load that can be applied to the intact beam (undamaged) in the middle of the span so that the beam does not buckle locally was $4373 \mathrm{~N}$, as summarized in Tab. 2 . 

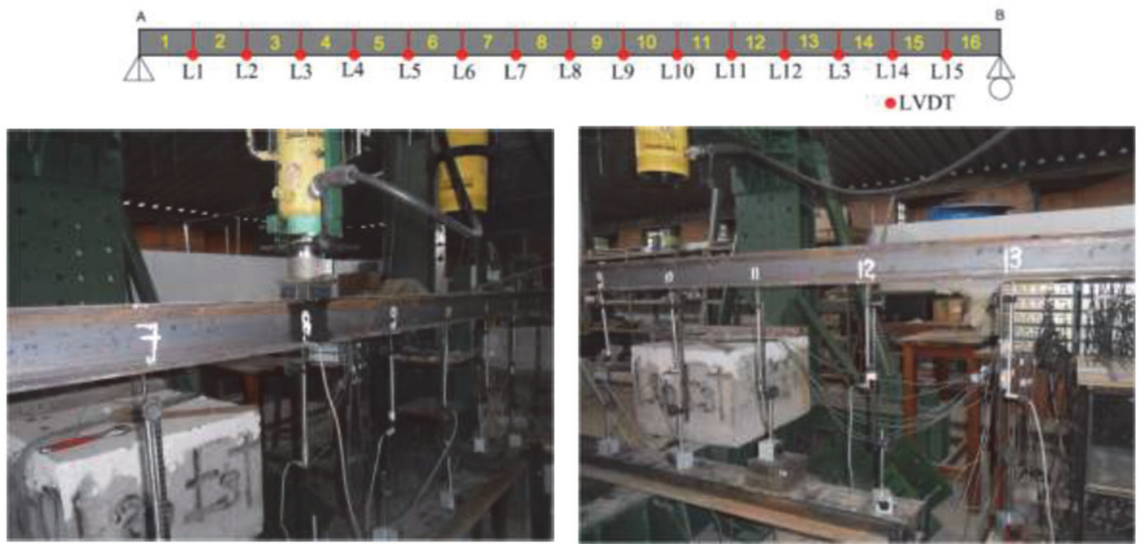

Figure 5: LVDT’s positions (16 parts) [15].

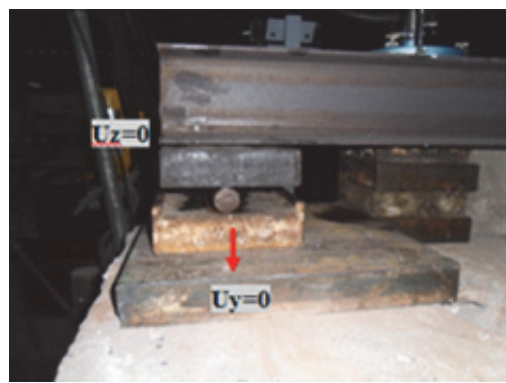

(a)

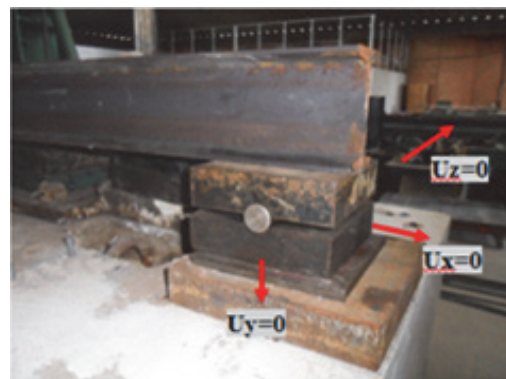

(b)

Figure 6: Support conditions of the steel beam specimen [15].
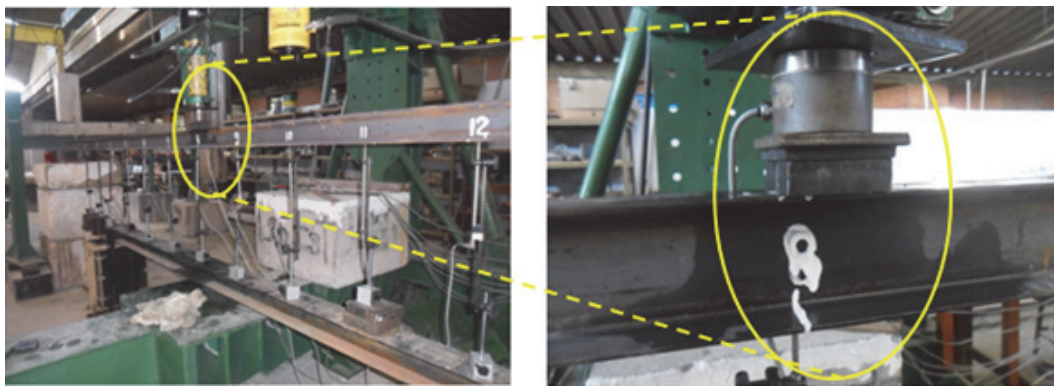

Figure 7: Loading details of the steel beam specimen [15].

\begin{tabular}{cc}
\hline Lateral buckling & Limits Loads \\
Web & $\mathrm{P}_{\max }=903 \mathrm{~kg}$ \\
Flange & $\mathrm{P}_{\max }=903 \mathrm{~kg}$ \\
Torsion & $\mathrm{P}_{\max }=438 \mathrm{~kg}=4373 \mathrm{~N}$
\end{tabular}

Table 2: Beam limits loads.

For the maximum load calculation, the intact beam data were considered, since the size and location of the damage is initially unknown. Considering the calculated maximum load, it can be analyzed in relation to a lower load due to the presence of imperfections in the beam (geometric and material imperfections) that can lead the part to reach the plastic regime. For this reason it was very important to apply in the structure load increments values immediately smaller than the maximum load. 


\section{NUMERICAL MODEL}

$\mathrm{N}$

umerical analyses were developed using the ANSYS ${ }^{\circ}$ (2007) software [14] in order to reproduce the same conditions of the above described experimental program. The elements adopted, BEAM3 or SHELL63, have three and six degrees of freedom by node, respectively, as illustrated in Fig. 8a and 8b.

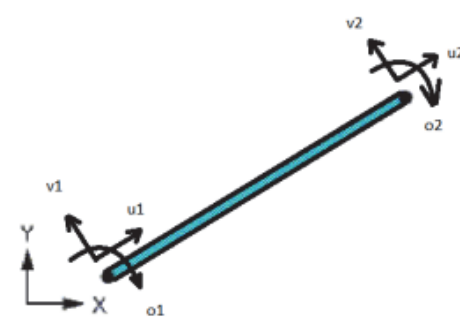

(a)
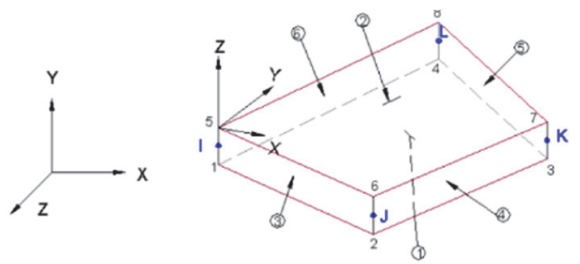

(b)

Figure 8: From ANSYSO (2007) library [15]: (a) BEAM3; (b) SHELL63 elements.

In order to simulate damage, the area and moment of inertia of the element cross section were reduced in BEAM3 model (Fig. 9), while and some elements were deleted for SHELL63 model (Fig. 10). The numerical models in Fig. 9 and 10 consider the same measurement points used in experimental test carried out by [15].

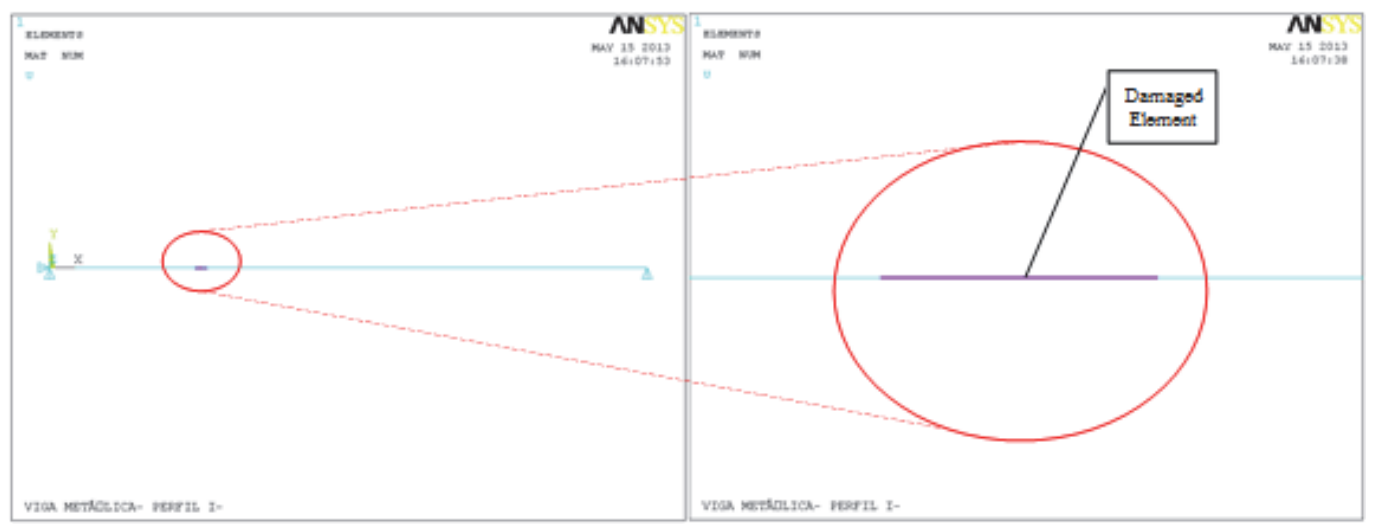

Figure 9: Damage simulation: BEAM3 element.
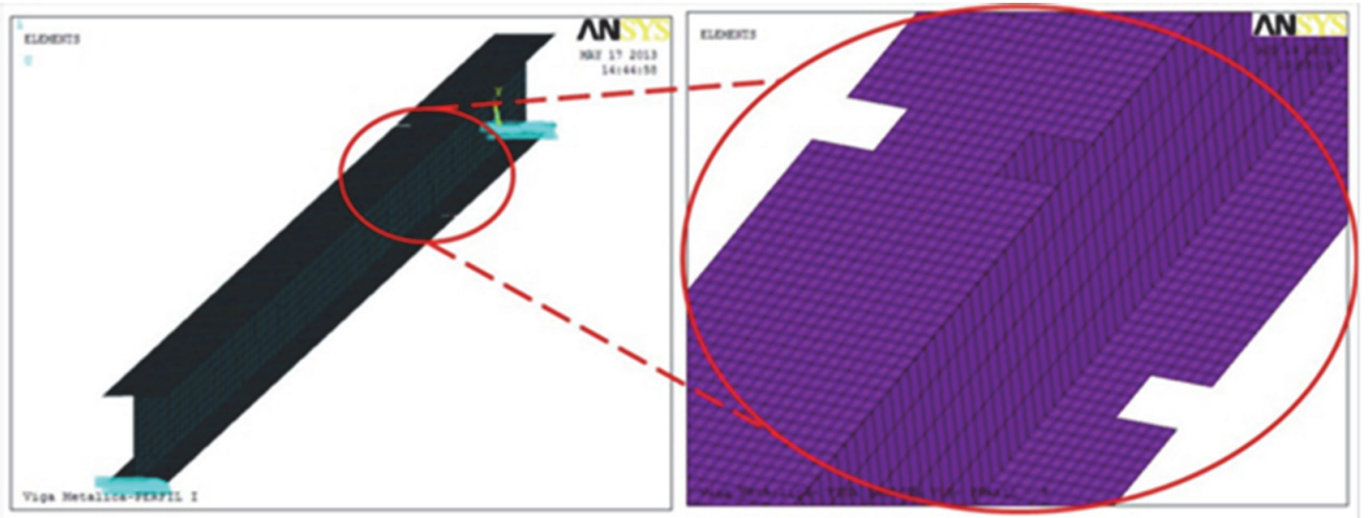

Figure 10: Damage simulation: SHELL63 element. 


\section{PROPOSED METHODOLOGY}

$\mathrm{O}$

he way to validate an analytical model is to compare its results with experimental ones. Problems of systems identification, also denominated as inverse problems, have applications in many areas of engineering, medicine and science in general. In these problems the fundamental properties are determined by observing the behavior of the system.

Some responses are related to variables which is possible to use to verify the agreement between the results of the analytical model and the experimental measures.

The objective function used is measured by least squares of the difference between the values obtained in the numerical model and in the experimental tests, see Eqn. (5) as follows:

$$
F=\int_{0}^{T}\left(x_{m}(t)-x(t)\right)^{2} d t
$$

where $\mathrm{x}(\mathrm{t})$ is obtained by the analytical model and $\mathrm{xm}(\mathrm{t})$ is the response measured experimentally in the time domain $\mathrm{t}$ in a time interval $[0, T]$. These parameters were adjusted to minimize the $\mathrm{F}$ function. In the identification of structural systems, normally mode shapes, natural frequencies and static displacements are selected as parameters to be used for identification of model. Thus, the best results will be obtained when the values of the objective function are closer to zero.

The proposed methodology is based on the use of a well-known Differential Evolution technique using numerical and experimental data of intact and damaged steel beams, see Fig. 11 and 12.

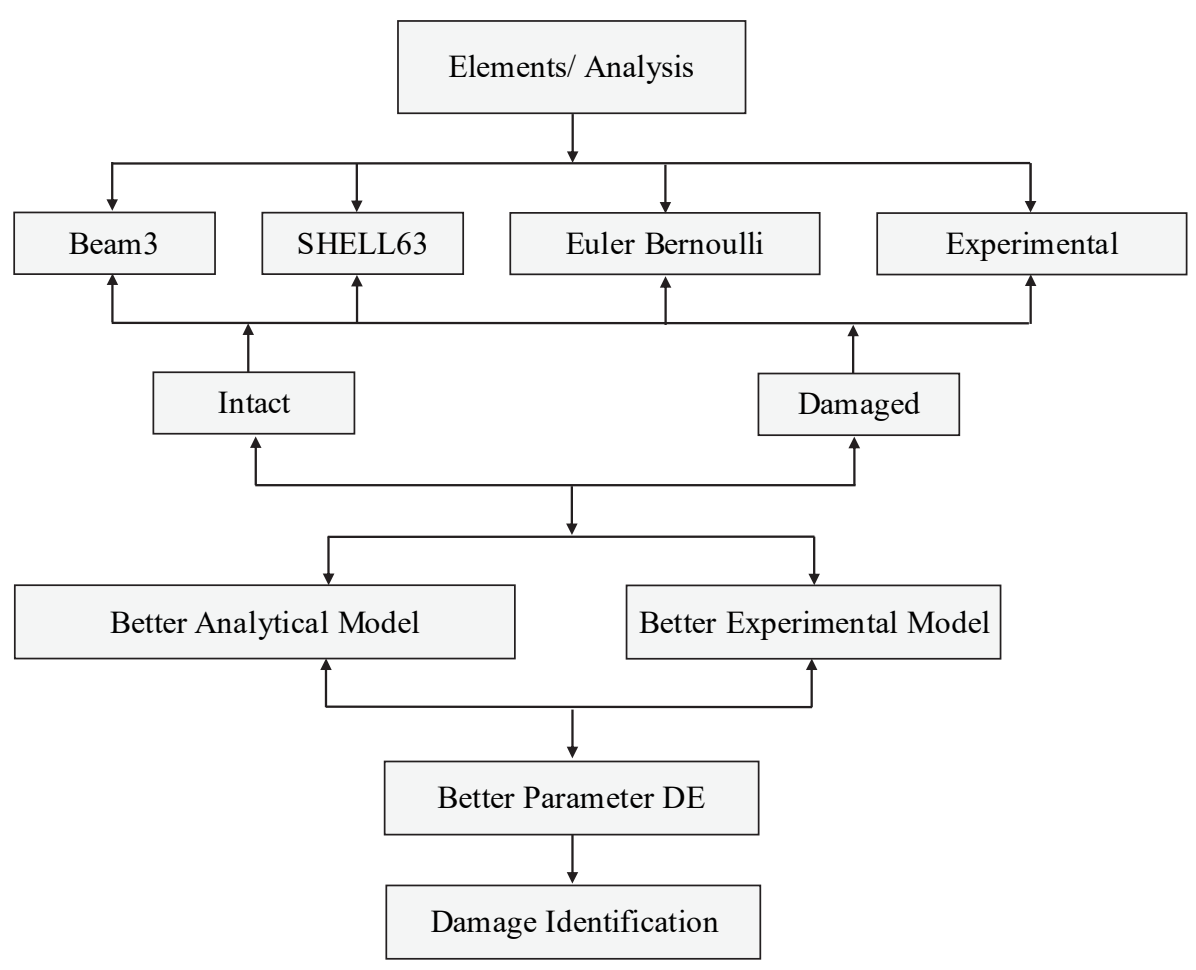

Figure 11: Flowchart analyses of Beam 1 (V3E).

It can be observed in the flowcharts (Fig. 11 and 12) the association of the DE method with the numerical and experimental data. For the Beam 1 (V3E) the numerical response (SHELL63 element) of the intact beam was used. For the Beam 2 (V5E) the numerical and experimental response of the intact structure was used. 


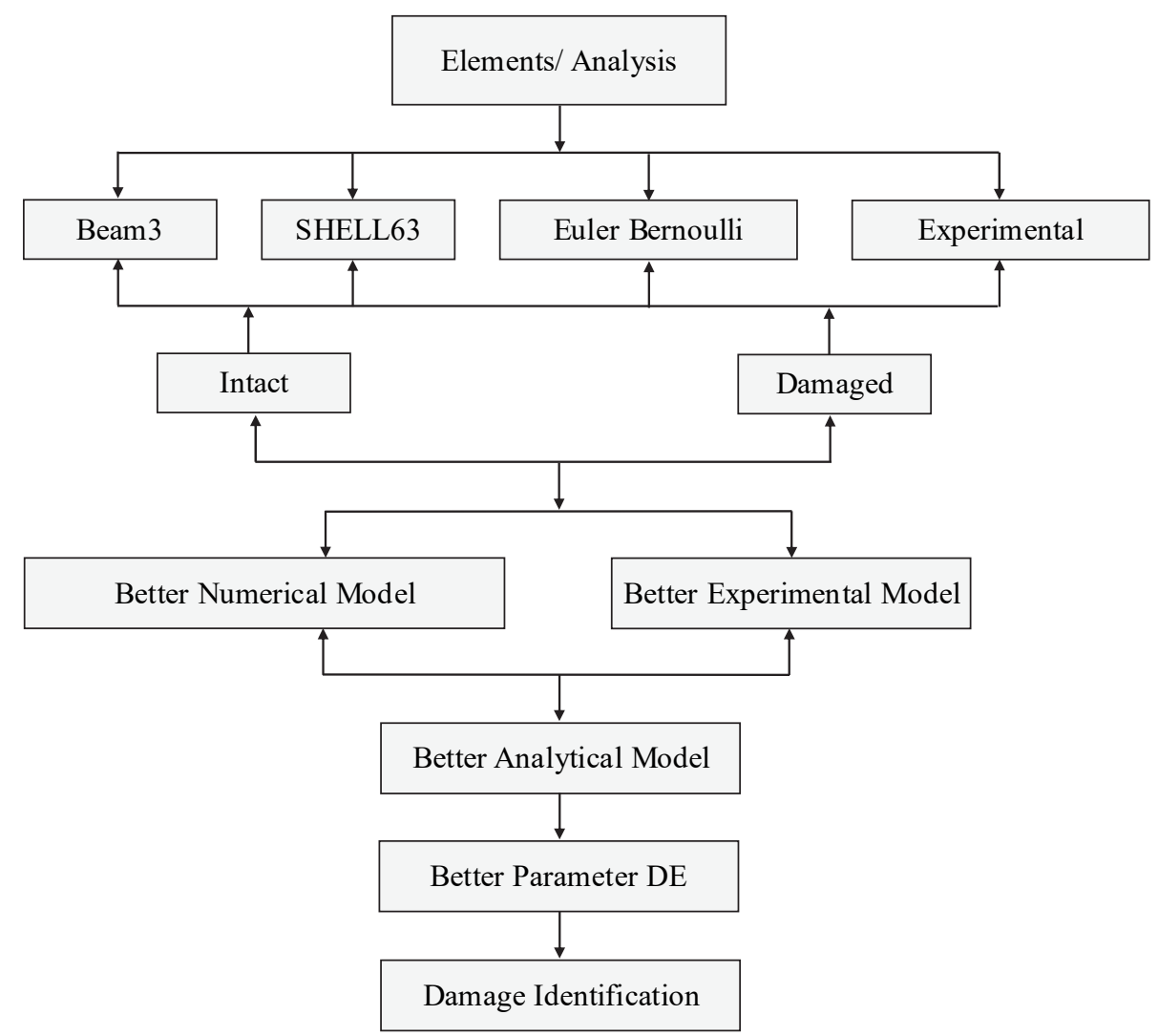

Figure 12: Flowchart analyses of Beam 2 (V5E).

\section{RESULTS}

$\mathrm{T}$

he models of the two beams are schematized in Fig. 13 and 14, in which the DE method was applied to different situations of beams with constant elements. In these different situations were used experimental static displacement results. The measured data were simulated by introducing two damaged elements (low stiffness) in finite element analyses and an elastic analysis was assumed.

In Fig. 13, the damage location occurs at $1.80 \mathrm{~m}$ and $4.20 \mathrm{~m}$ from left support, with damage of $2 \mathrm{~cm}$ length $(45 \%)$ in each side, in correspondence of an applied load of $4350 \mathrm{~N}$ in the middle of the span. In Fig. 14, damage is located at the middle of the span $(3.00 \mathrm{~m})$, for an applied load of $2000 \mathrm{~N}$ in both beam sides.

\section{Beam 1 (V3E): Load 4350N}

The plot of displacements of intact and damaged Beam 1 (V3E) is presented in Fig. 15, which reports the displacements obtained along the beam length generated by applying a load of $4350 \mathrm{~N}$. The exam of this diagram can help to analysis the coherence of the elements used in the analytical method, as well as to verify the experimental model, in terms of intact and damaged situations.
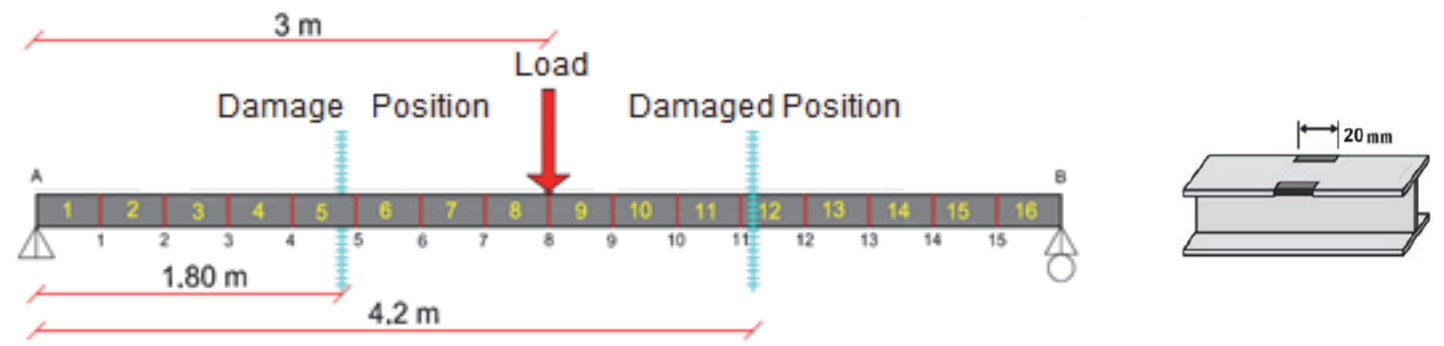

Figure 13: Damaged Beam 1 (V3E). 

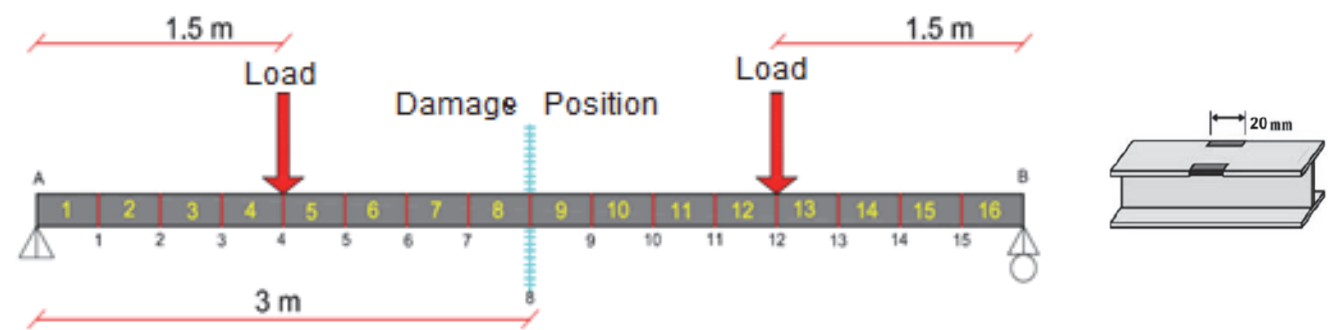

Figure 14: Damaged Beam 2 (V5E).
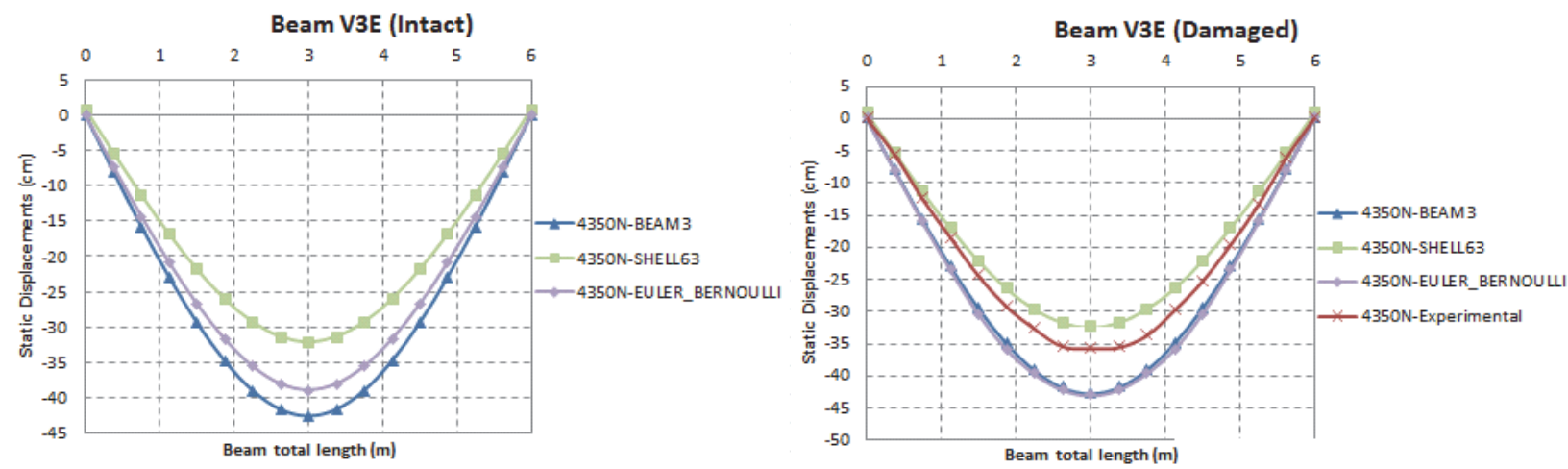

Figure 15: Plot of displacements for the intact and damaged Beam 1 - V3E (load 4350N).

In the following numerical results obtained from simulations with BEAM3 and SHELL63 elements, Euler-Bernoulli theory, as well as through a proposed simulation that relates the intact model to the damaged experimental model, whose goal is to identify damaged elements in the structure, are presented in Tab. 3.

\begin{tabular}{|c|c|c|c|c|c|c|c|}
\hline Item & Beam & $\begin{array}{l}\text { Load } \\
(\mathrm{N})\end{array}$ & $\begin{array}{l}\text { Elements / } \\
\text { Analyses }\end{array}$ & Iterations & $\begin{array}{l}\text { Damaged } \\
\text { Elements }\end{array}$ & $\begin{array}{c}\% \text { of } \\
\text { Damage }\end{array}$ & $\begin{array}{l}\text { Objective } \\
\text { Function } \\
\text { Minimum }\end{array}$ \\
\hline \multirow{4}{*}{1} & \multirow{4}{*}{$\begin{array}{c}\text { Beam } 1 \\
\text { (V3E) }\end{array}$} & \multirow{4}{*}{4350} & BEAM3 & 50th & 5 and 12 & $45 \%$ & 0.72466525 \\
\hline & & & SHELL63 & 50 th & 5 and 12 & $45 \%$ & 2.01215635 \\
\hline & & & Euler-Bernoulli & 50th & 5 and 12 & $45 \%$ & 183.19207908 \\
\hline & & & Experimental & 100th & 5 and 12 & $45 \%$ & 148.31064460 \\
\hline
\end{tabular}

Table 3: Results for the Beam1 (V3E).

Fig. 16 shows the analyses of the problem solution using the BEAM3 element, which provides values in agreement with the considered problem, finding few residues.

In Fig. 17, using the SHELL63 element, it is verified that the damaged values of the elements are in agreement with the considered problem, where there are some distortions, probably, due to not null displacements close to supports.

Fig. 18 shows the analyses of the problem solution and the damage values of the elements obtained by using Euler-Bernoulli theory. These values are in agreement with the problem proposed with minor variations, but with good results.

In Fig. 19, the results obtained from the proposed numerical simulation of the intact beam are compared to those obtained by the experimental damaged beam. These comparisons between the intact plot analyses and the damaged (experimental) one are provided in terms of displacements along beam length for Beam 1 (V3E), in correspondence of a load application of $4350 \mathrm{~N}$. 


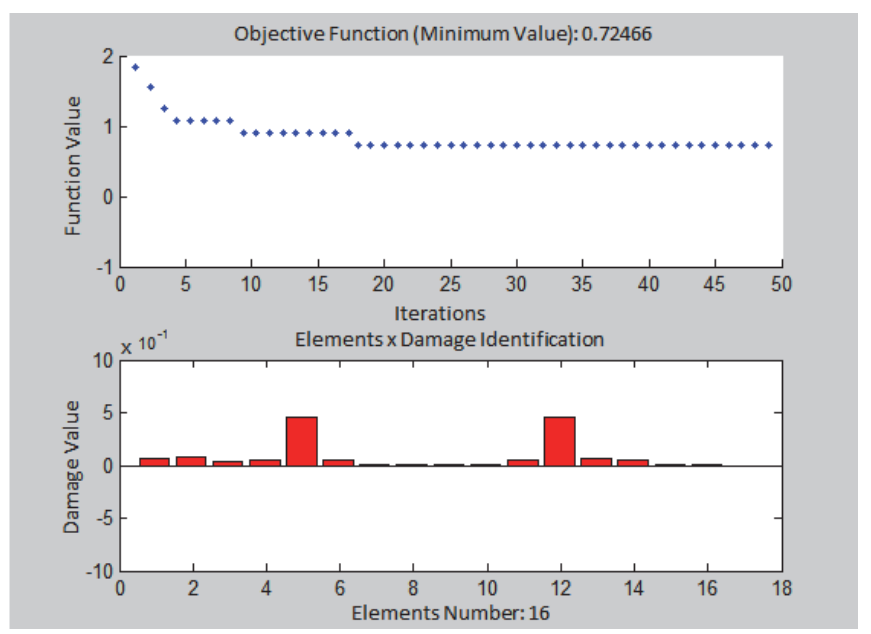

Figure 16: Damage identification: Beam 1 - V3E, load 4350N (BEAM3).

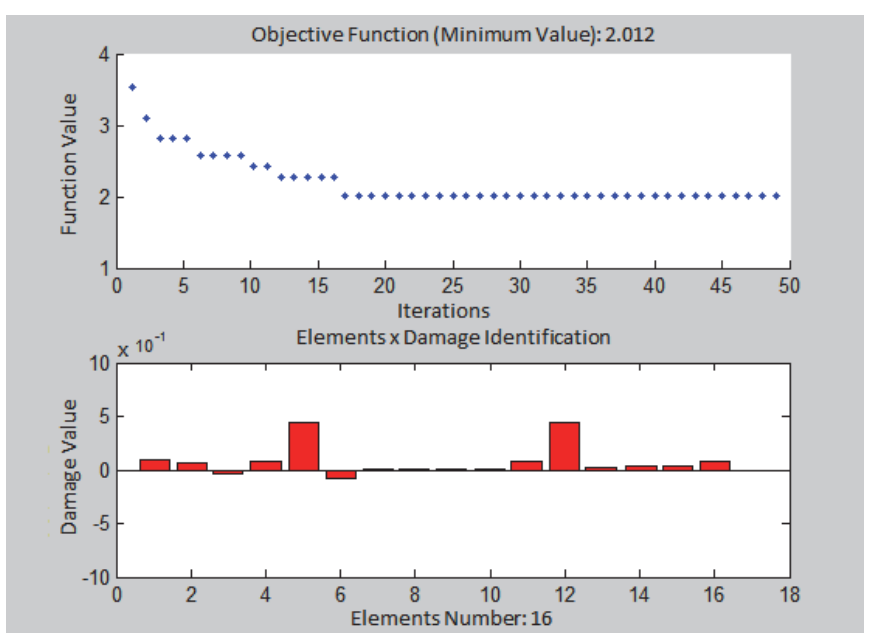

Figure 17: Damage identification: Beam 1 - V3E, load 4350N (SHELL63).

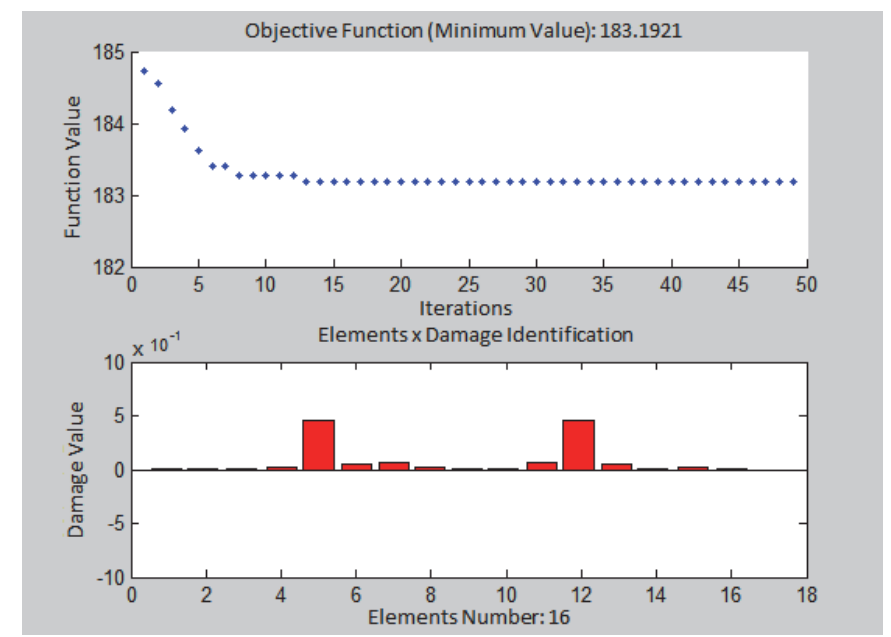

Figure 18: Damage identification: Beam 1 - V3E, load 4350N (EULER-BERNOULLI). 


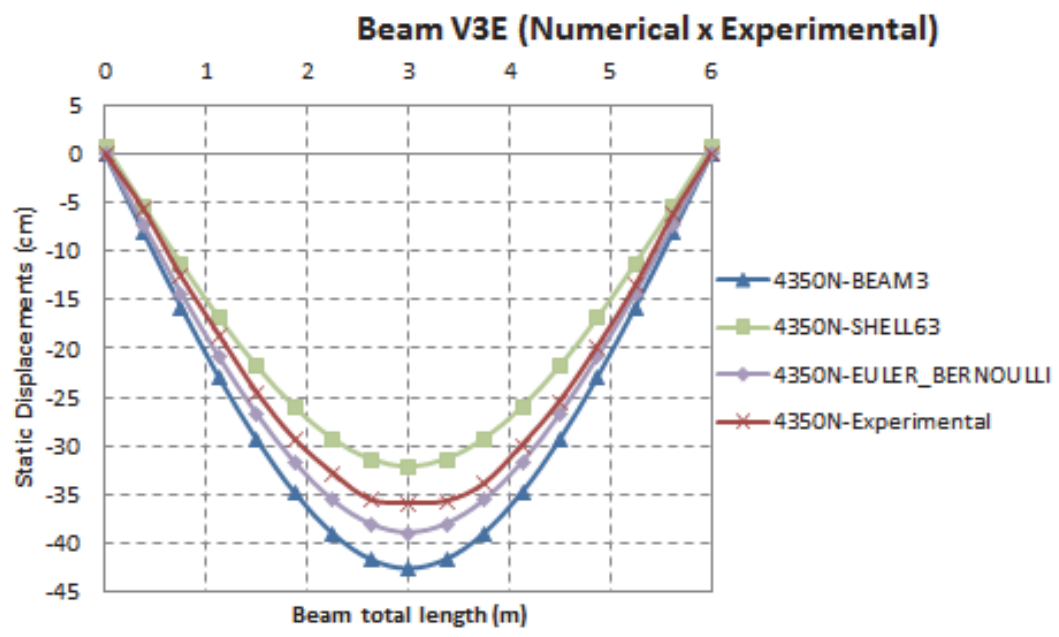

Figure 19: Intact (numerical) and damaged (experimental) displacements for the Beam 1 - V3E (load 4350N).

This attempt of damage identification analysis is already possible because the displacements obtained in the ANSYS ${ }^{\odot}$ (2007) intact numerical analysis by means of the SHELL63 element have values lower than those obtained in the damaged analysis through the experimental model, demonstrating possibilities of coherence in the analysis. It can be explained by the fact that this element presents simulation conditions near to what was applied in the experimental analysis.

This simulation of the fourth approach intends to obtain result values in the intact numerical analyses of the ANSYS ${ }^{\odot}$ (2007), through element SHELL63 together with the experimental damaged analysis, used to identify a damaged element in the structure. In this analyses were only considered static displacements values of beam elements. Fig. 20 presents the analysis of the problem solution results. The element's damage values are in agreement with the proposed problem, even if at the beginning and end of damage analyses appeared some distortions probably due to not null displacements close to supports.

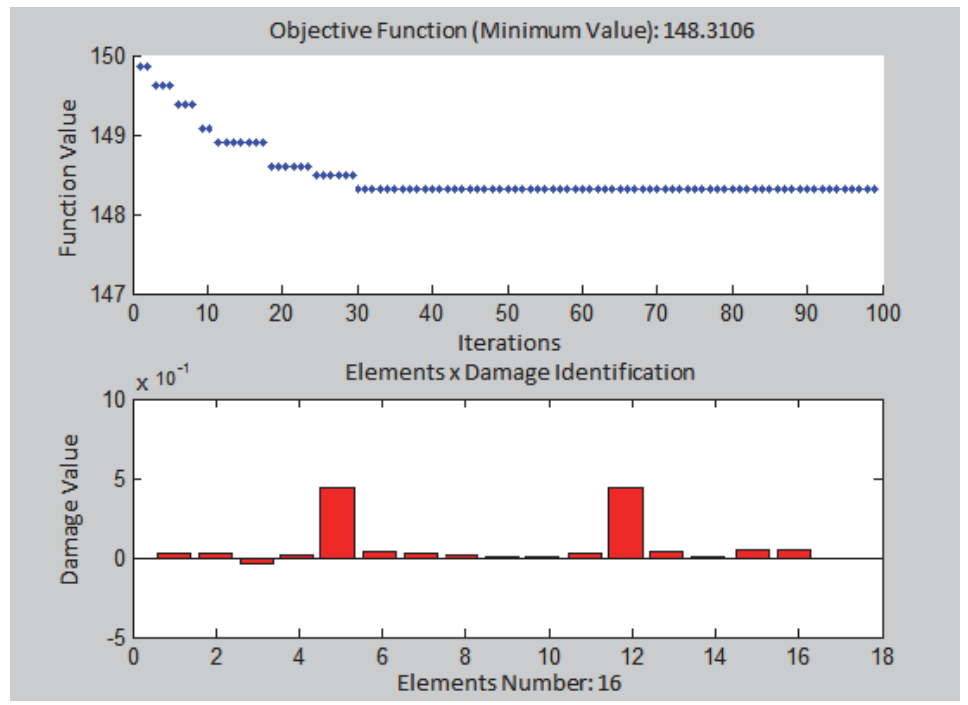

Figure 20: Damage identification: Beam 1 - V3E, load 4350N (Numerical x Experimental).

The damage identification analyzed in this example was restricted to the displacements obtained in the intact and damaged numerical analyses using a small number of iterations that generate the presence of residues of damages identification in other elements.

Mainly where there were large displacement differences (whether negative results), the presence of point loads, the area next to supports or even next to damaged regions, nevertheless the damage values of the elements follow the proposed problem. It is emphasized that the increase in the number of iterations, in some cases, helps to solve the problem of local minimum approximation. 
In the analyses of Beam 1 (V3E), it can also be pointed out that a big number of displacements information also would help in the optimizing procedure. The answers had relatively fast characteristics of convergence, considering the small amount of involved iterations. Even so, the tool attended to the localization capacity and damage quantification in any element of the structure in study.

\section{Beam 2 (V5E): Load 2000N}

In the intact and damaged analyses according to Beam 2 (V5E), displacements plots are presented in Fig. 21, where the xaxis (abscissa) corresponds to the length of the beam $(6.00 \mathrm{~m})$ and the $y$-axis (ordinate) correspond to displacements generated by application of $2000 \mathrm{~N}$ load. This demonstration is necessary again to establish an analysis of the coherence of the elements used, as well as the analytical method, without the verified experimental model, but always in terms of intact and damaged situations, verifying the DE method potential in the numerical analyses.
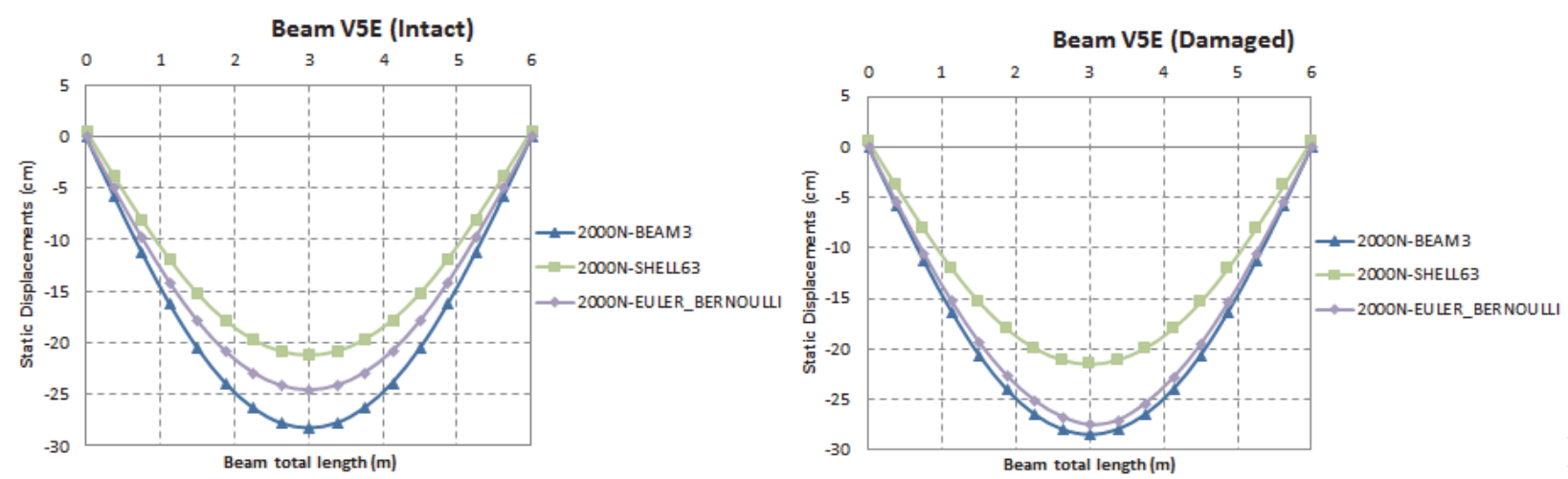

Figure 21: Intact and damaged analyses corresponding to the displacements for the Beam 2 - V5E (load 2000N).

For the Beam 2 (V5E) analyses, the obtained results for the considered problem solutions are showed in Tab. 4.

\begin{tabular}{ccccccc}
\hline Item & Beam Load (N) & $\begin{array}{c}\text { Elements } / \\
\text { Analyses }\end{array}$ & Iterations & $\begin{array}{c}\text { Damaged } \\
\text { Elements }\end{array}$ & $\begin{array}{c}\text { \% of } \\
\text { Damage }\end{array}$ & $\begin{array}{c}\text { Objective } \\
\text { Function } \\
\text { Minimum }\end{array}$ \\
$1 \quad \begin{array}{c}\text { Beam 2 } \\
\text { (V5E) }\end{array}$ & 2000 & SHELL63 & 100th & 9 & $45 \%$ & 0.51703227 \\
\hline
\end{tabular}

Table 4: Results for the Beam 2 (V5E).

Fig. 22 shows the analyses of the problem solution using the element BEAM3 that is in agreement with the considered problem.

The proposed simulations in the second approach was carried out using SHELL63 element. Fig. 23 shows the problem solution result. Only the values of the static displacements of the beam elements were again considered, with the damage values of the elements in agreement with the considered problem.

The results of the third approach with Euler-Bernoulli theory are show in Fig. 24 the result of the problem solution. This case presented damaged values in agreement to the considered problem.

In the analyses with BEAM3 element, there are some damage residues close to the damaged element, still with close values. In the case of SHELL63 element, at the beginning and end of damage analyses some residues were observed, probably due to non-zero displacements close to supports. Anyway, good results were achieved, due to a big number of iterations. Finally, the analyses with EULER-BERNOULLI, presented some perturbations, but with the values of damages of the elements in agreement with the problem considered good results were obtained, although the minimum of the objective function for being a little big. 


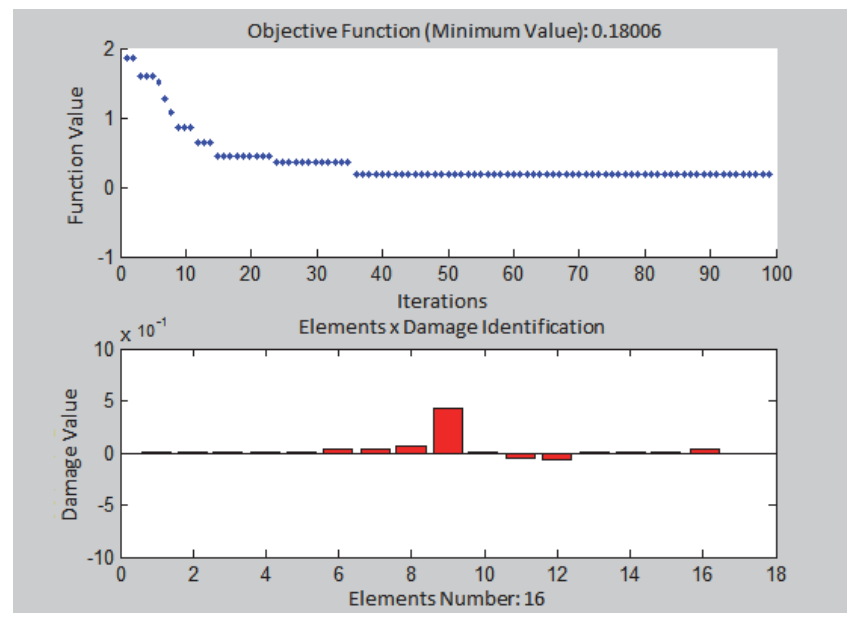

Figure 22: Damage identification: Beam 2 - V5E, load 2000N (BEAM3).

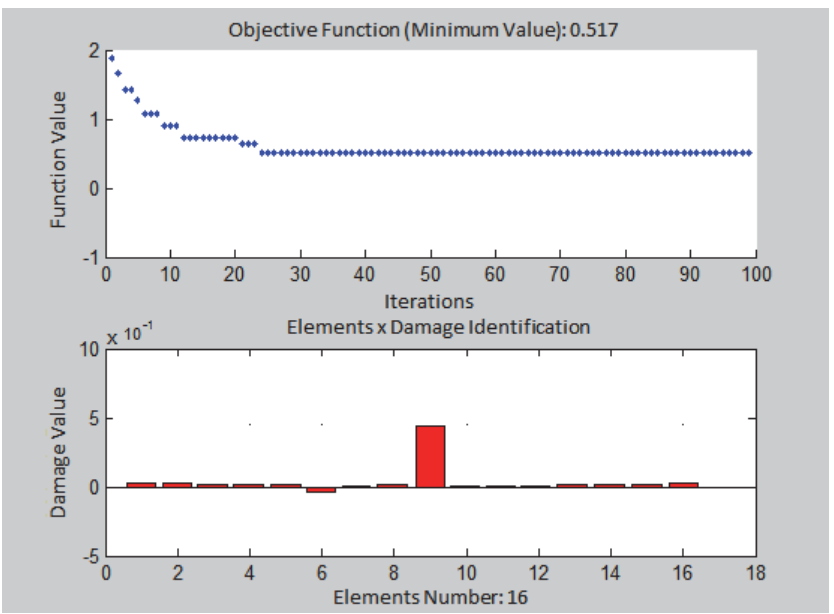

Figure 23: Damage identification: Beam 2 - V5E, load 2000N (SHELL63).

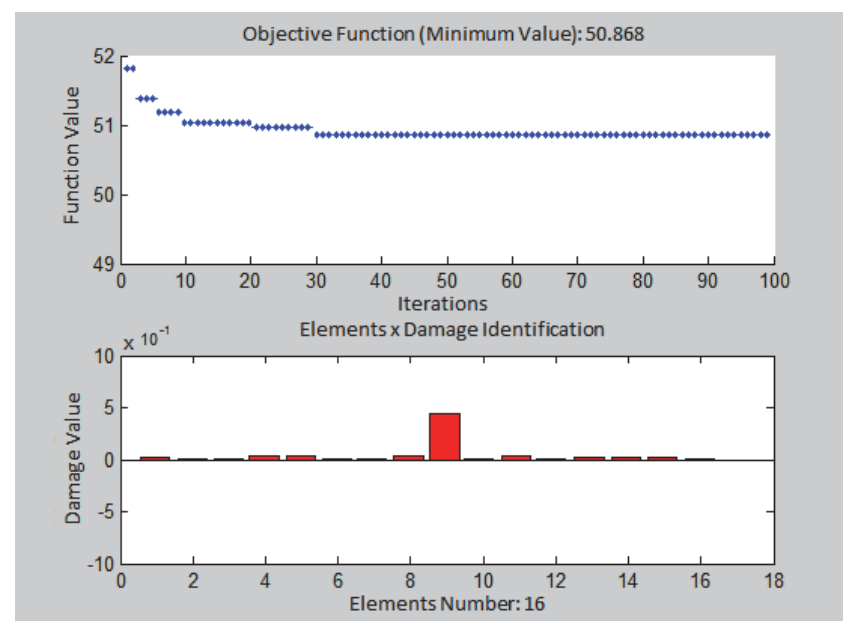

Figure 24: Damage identification: Beam 2 - V5E, load 2000N (EULER-BERNOULLI). 
The damage identification analyses in this example was restricted to the displacements obtained in intact and damaged numerical analyses.

With the analyses of Beam 2 (V5E), it can also be affirmed that a big number of displacements information also would assist in the optimizing procedure. The answers had relatively fast characteristics of convergence, considering the small amount of involved iterations. Even so, the tool was able to localize and quantify damage in any element of the structure in study.

\section{CONCLUSIONS}

$\mathrm{T}$ he structural responses of steel beams under different loading conditions were used in conjunction with DE method in order to detect structural damage.

The design variables considered in the objective function minimization problem were the intact and damaged structural responses. These variables were continuously changed in order to allow the response obtained by the analytical model to approximate the experimental response.

The Differential Evolution Method turned out to be a good method for solve problems of damage identification, since it converges to a correct solution in all cases.

The Euler-Bernoulli beam model was used because it is a simplification of the linear theory of elasticity that provides a way to calculate the deflection characteristics of a beam subjected to bending under a given load (static or dynamic). It is an ideal theory for use in beams with lower heights, such as the cases studied in this research. The consistency of the results obtained from static displacements with the other methods and the experimental results was also one of the determining factors of this use of Euler Bernoulli's theory.

The characteristic of the difference distribution vector could be analyzed as a convergence parameter and it was possible to find localized solutions at regions where there is a minimum point.

All these aspects were considered in the present research and at hence the results were validated since the damages were detected successfully.

\section{ACKNOWLEDGMENTS}

he Authors thank the Graduate Program in Structural Engineering and Civil Construction of the Department of Civil and Environmental Engineering at the University of Brasilia, Brazil.

\section{REFERENCES}

[1] Rus, G. and Gallego, R. (2002). Optimization algorithms for identification inverse problems with the boundary element method. Engineering Analysis with Boundary Elements, 26, pp. 315-327. DOI: 10.1016/s0955-7997(02)00008-5.

[2] Pnevmatikos, N. G., Blachowski, B., Hatzigeorgiou, G. D. and Swiercz, A. (2016). Wavelet analysis based damage localization in steel frames with bolted connections, Smart Structures and System, 18(6), pp.1189-1202. DOI: 10.12989/sss.2016.18.6.1189.

[3] Pnevmatikos, N. G. and Hatzigeorgiou, G. D. (2016). Damage detection of frame structures subjected to earthquake excitation using discrete wavelet analysis, Bulletin of Earthquake Engineering, 15(1), 227-248. DOI: $10.1007 / \mathrm{s} 10518-016-9962-z$.

[4] Palechor, E. U. L., Silva, R. S .Y. R. C., Bezerra, L. M. and Bittencourt, T. N. (2014). Damage detection in beams using experimental data. Key Eng. Materials, v. 607, 21-29. DOI: 10.4028/www.scientific.net/KEM.607.21.

[5] Lopes, P. S. (2010). Inverse problem modeling of damage detection by parameter identification and optimization techniques. Doctoral thesis - Federal University of Itajubá, Brazil (Doctoral thesis).

[6] Vigdergauz, S. (2003). Combined Upper Bounds on the Effective Moduli of a Perforated Elastic Plate. Numerical Assesment by Genetic Algorithm. Mathematics and Mechanics of Solids. DOI: 10.1177/1081286505040404.

[7] Barbosa, H. J., Bernardino, H. S. and Barreto, A. M. (2013). Using Performance Profiles for the Analysis and Design of Benchmark Experiments. In Advances in Metaheuristics, 21-36. Springer, New York.

DOI: 10.1007/978-1-4614-6322-1_2. 
[8] Storn, R. and Price, K. (1997). Differential evolution - A simple and efficient heuristic for global optimization over continuous spaces. J. Global Optimiz., 11, pp. 341-359.

[9] Suveges, J. M. C. (2014). Study on Detection of Damage in Structures via Optimization Method. Master thesis, Federal University of Itajubá, Brazil (Masters dissertation).

[10] Santos, G. F. (2009). Identification of structural damages using optimization techniques. Master thesis - Rio de Janeiro State University, Rio de Janeiro, Brazil (Masters dissertation).

[11] Kleinermann, J. P. (2000). Identification Parametrique et Optimization des Procèdès de Mise a Forme par Problemes Inverses. Unpublished doctoral dissertation. University of Liege. Liege, Belgium (Doctoral thesis).

[12] Cury, A., Borges, C. and Barbosa, F. (2011). A two-step technique for damage assessment using numerical and experimental vibration data, Structural Health Monitoring, 10, pp. 417-428. DOI: 10.1177/1475921710379513.

[13] Alves, V. N. (2012). Study of new strategies for identifying structural damage from vibrational data. Master thesis, Federal University of Ouro Preto, Brazil. (Masters dissertation).

[14] ANSYS (2007). Structural analysis guide - release 11.0. In: ANSYS ${ }^{\circ}$.

[15] Palechor, E. U. L. (2013). Identification of Damage in Metal Beams Using Wavelets and Numerical and Experimental Data. Master thesis, University of Brasilia, Brazil (Masters dissertation). 